\title{
2 Cases of Acute Confusional State with Autonomic Symptoms after Designer Tryptamine Abuse
}

\section{Hisashi Ito*, Shigeru Fukutake and Tetsumasa Kamei}

Department of Neurology, Shonan Fujisawa Tokushukai Hospital, Fujisawa, Japan

${ }^{*}$ Corresponding author: Dr. Hisashi Ito, Department of Neurology, Shonan Fujisawa Tokushukai Hospital, 251-0041, Fujisawa, Japan, Tel: +81-466-35-1177; Fax: +81-466-35-1300; E-mail: hisashi.ito@tokushukai.jp

Rec Date: July 12, 2018; Acc Date: July 20, 2018, 2018; Pub Date: July 23, 2018

Citation: Ito H, Fukutake S, Kamei T (2018) 2 Cases of Acute Confusional State with Autonomic Symptoms after Designer Tryptamine Abuse. J Neurol Neurosci Vol.9 No.4:264

\section{Abstract}

We herein report 2 cases of acute tryptamine abuse. Both cases developed confusional state within 1 hour of 4acetoxy-N-methyl-N-isopropyl-tryptamine ingestion. On admission, they presented confusion with marked mydriasis. In addition, one case showed hypertension, low grade fever, and hyperhidrosis, and the other showed the contraction of pilomotor muscles. Confusion and other autonomic symptoms improved gradually with intravenous drip infusion of saline. Tryptamine abuse should be considered as differential diagnosis in cases of acute confusional state with various autonomic symptoms.

Keywords: 4-acetoxy-N-methyl- $\mathrm{N}$-isopropyl-tryptamine; Confusional state; Autonomic symptoms

\section{Introduction}

Designer tryptamine such as 5-methoxy-N, Ndiisopropyltryptamine (5-MeO-DIPT) and 5-methoxy-N-methyl$\mathrm{N}$-isopropyltryptamine (5-MeO-IPT) have been restricted legally in Japan. However, these tryptamine analogs are popular among recreational drug users because of their hallucinogens. Previous reports described neuropsychiatric symptoms by these drugs are limited [1-4]. We report 2 cases of acute confusional state and multiple autonomic symptoms after oral ingestion of 4-acetoxy- $\mathrm{N}$-methyl- $\mathrm{N}$-isopropyltryptamine (4-AcO-MIPT).

\section{Case Presentation}

\section{Case 1}

A 27-year-old Japanese man was brought to the emergency room because he was excited after 30 minutes from ingestion of $10 \mathrm{mg}$ of 4-AcO-MIPT (Figure 1). On examination, he was not oriented with a Glasgow Coma Scale score of 12 (E4V3M5). He smiled and shouted with looking around restlessly and could not communicate properly with medical staffs. Blood pressure was $156 / 112 \mathrm{mmHg}$, heart rate was $140 /$ minutes, and body temperature was $37.5{ }^{\circ} \mathrm{C}$ He presented severe hyperhidrosis. Pupils were $8 \mathrm{~mm}$ in diameter equally without response to light. No nystagmus, weakness, asterixis, pathological reflex, and neck stiffness were observed. Routine laboratory examination was normal except for the positive reaction of amphetamine. Brain CT showed normal.

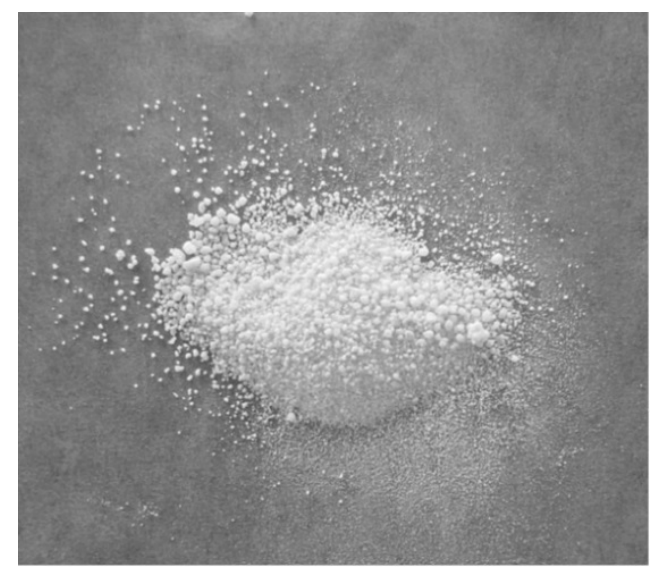

Figure 1 4-AcO-MIPT which our 2 cases ingested.

We injected $15 \mathrm{mg}$ of diazepam to resolve the agitative state. He was able to answer some questions about 2 hours after receiving an intravenous drip infusion of saline. He became alert after 6 hours after admission. He remembered neither nausea nor visual hallucinations, but the brightness and sweating after taking 4-AcO-MIPT. He was discharged the next day without neurological deficit other than a partial anterograde amnesia.

\section{Case 2}

A 27-year-old Japanese woman, who was a wife of case 1, was brought to the emergency room as she developed nausea following disorganized behavior after 30 minutes from the ingestion of $5 \mathrm{mg}$ of 4-AcO-MIPT. On examination, she was not oriented with a Glasgow Coma Scale score of 14 (E4V4M6). She sat on the stretcher without expression. She was able to answer some questions and apologized repeatedly. Blood pressure was $120 / 76 \mathrm{mmHg}$, heart rate was $152 /$ minutes, and 
body temperature was $36.0^{\circ} \mathrm{C}$. She presented the contraction of pilomotor muscles. Pupils were $7 \mathrm{~mm}$ in diameter equally with slight response to light. No nystagmus, weakness, asterixis, pathological reflex, and neck stiffness were observed. Routine laboratory examination and screening of illegal drugs were normal. Brain CT showed normal.

We injected $10 \mathrm{mg}$ of diazepam because she suddenly stood up on the stretcher with screaming. She became alert about 2 hours after receiving an intravenous drip infusion of saline. She remembered neither visual hallucinations nor sweating, but the brightness and nausea after taking 4-AcO-MIPT. She was discharged the next day without neurological deficit other than a partial anterograde amnesia.

\section{Discussion}

Several drugs are regulated legally as 'designated drugs' in Japan and more than 10 kinds of tryptamine analogs were listed for restriction. 4-AcO-MIPT has also been restricted legally since 2015. The synthetic 4-substituted tryptamines including 4-AcO-MIPT seem to have similar actions; however, scientific information of these drugs is limited. The hallucinogenic effects of 4-hydroxydimethyltryptamine $(4-\mathrm{OH}$ DMT, Psilocin), which is a representative 4-substituted tryptamine, arise within 2 hours and disappear within 4 to 8 hours [5]. 4-OH-DMT is an agonist for 5- $\mathrm{HT}_{2 \mathrm{~A}}$ and other serotonin receptors, which leads to sympathetic stimulations with hallucinogenic effects $[6,7]$.

As far as our literature searches, only one case of 4-AcOMIPT abuse has been published in Japanese [2]. Ando and his colleagues reported a 28-year-old Japanese man presented consciousness disturbance, disinhibitory behavior, visual hallucination, nausea, hyperhidrosis, and mild mydriasis after 4-AcO-MIPT ingestion. Our 2 cases also presented consciousness disturbance and disinhibitory behavior with various autonomic symptoms.
The offending drug in our cases was informed as 4-AcOMIPT on admission however, it is difficult to identify the offending drug from patients' information alone. Gas chromatography-mass spectrometry and liquid chromatography- mass spectrometry was useful to identify the offending drug [1]. However, these laboratory equipment's were not popular. It is important to regard tryptamine analogs as one of the causes of acute confusional state with autonomic symptoms.

\section{References}

1. Itokawa M, Iwata K, Takahashi M, Sugihara G, Sasaki T, et al. (2007) Acute confusional state after designer tryptamine abuse. Psychiatry Clin Neurosci 61: 196-199.

2. Andoh H, Ichimura A, Yano H, Ohya A, Enseki Y, et al. (2007) A case of jumping with perceptual alteration, visual hallucination, consciousness disturbance and disinhibitory behavior, due to overdose of 4-acetoxy-N-methyl-N-isopropyl-tryptamine (4-AcOMIPT). Clinical Psychiatry 49: 189-192.

3. Fuse-Nagase $Y$, Nishikawa T (2013) Prolonged delusional state triggered by repeated ingestion of aromatic liquid in a past 5methoxy-N, N-diisopropyltryptamine abuser. Addict Sci Clin Pract 8: 9.

4. Coppola M, Mondola R (2013) A new stimulant of abuse: 5-(2aminopropyl) indole. Am J Psychiatry 170: 226.

5. Tittarelli R, Mannocchi G, Pantano F, Romolo FS (2015) Recreational use, analysis and toxicity of tryptamines. Curr Neuropharmacol 13: 26-46.

6. Hill SL, Thomas SH (2011) Clinical toxicology of newer recreational drugs. Clin Toxicol 49: 705-719.

7. Peden NR, Macaulay KEC, Bisset AF, Crooks J, Pelosi AJ (1981) Clinical toxicology of 'magic mushroom' ingestion. Postgrad Med J 57: 543-545. 